\title{
Air-entrainment characteristics in a plunging water jet system using rectangular nozzles with rounded ends
}

\author{
Tamer Bagatur ${ }^{1}$ and Nusret Sekerdag ${ }^{2}$ \\ ${ }^{1}$ Firat University, Department of Civil Engineering, Elazig, Turkey \\ ${ }^{2}$ Firat University, Department of Environmental Engineering, Elazig, Turkey
}

\begin{abstract}
When a water jet impinges a pool of water at rest, air bubbles may be entrained and carried some way below the pool's free surface. This process is called air-entrainment or aeration by a plunging water jet. In this study, air-entrainment characteristics such as volumetric airflow rate, air-entrainment rate, and bubble penetration depth in a plunging jet system using inclined rectangular nozzles with rounded ends were studied depending on effective jet width at impact point. An empirical correlation for an inclined rectangular nozzle with rounded ends is presented to predict the air-entrainment rate as a function of effective jet expansion ratio.
\end{abstract}

\section{Nomenclature}

$\mathrm{a}_{\mathrm{n}} \quad:$ nozzle outlet height, $\mathrm{m}$

$\mathrm{b}_{\mathrm{n}} \quad$ : nozzle outlet width, $\mathrm{m}$

$b_{j} \quad:$ effective jet width at plunge point, $m$

$\mathrm{d}_{\mathrm{n}} \quad$ : nozzle diameter, $\mathrm{m}$

$d_{j} \quad$ : effective jet diameter at plunge point, $m$

$\mathrm{H}_{\mathrm{p}} \quad$ : bubble penetration depth, $\mathrm{m}$

$\mathrm{L}_{\mathrm{n}} \quad$ : nozzle length, $\mathrm{m}$

$\mathrm{L}_{\mathrm{j}} \quad$ : water jet length, $\mathrm{m}$

$\mathrm{Q}_{\mathrm{a}} \quad$ : volumetric airflow rate, $\mathrm{m}^{3} \cdot \mathrm{s}^{-1}$

$\mathrm{Q}_{\mathrm{w}} \quad$ : volumetric water flow rate, $\mathrm{m}^{3} \cdot \mathrm{s}^{-1}$

$\mathrm{Q}_{\mathrm{a}} / \mathrm{Q}_{\mathrm{w}}:$ air-entrainment rate (-)

$\mathrm{V}_{\mathrm{j}} \quad$ : water jet velocity, $\mathrm{m} \cdot \mathrm{s}^{-1}$

$\theta \quad$ : nozzle angle, degree

\section{Introduction}

A plunging water jet passing through the surrounding air entrains a large amount of air bubbles into a pool and forms a large submerged two-phase (gas-liquid) contacting area. Plunging water jets are encountered in a wide variety of industrial and environmental situations. Water jets are used to stir chemicals (e.g., jet mixer) and to increase gas-liquid transfer (e.g., oxygen transfer). Moreover, plunging water jets have applications such as aeration and flotation processes in sewage and water treatment plants (Bin, 1993).

For circular water jets, Henderson et al. (1970) defined the ratio of airflow to water flow by an empirical correlation for high velocity water jets:

$$
\mathrm{Q}_{\mathrm{a}} / \mathrm{Q}_{\mathrm{w}}=\left(\mathrm{d}_{\mathrm{j}} / \mathrm{d}_{\mathrm{n}}\right)^{2}-1
$$

where:

$d_{j}$ and $d_{n}$ are the effective or the mean local jet diameter at plunge point and circular nozzle diameter, respectively.

\footnotetext{
* To whom all correspondence should be addressed.

푱90 424 2386911; fax: 90424 2386921; e-mail: tbagatur@yahoo.com Received 22 July 2002; accepted in revised form 25 October 2002.
}

This equation implies that only the air within the diameter that contains the surface roughness is brought below the water surface.

Evans et al. (1996) measured the change in effective jet diameter $\left(d_{j}\right)$ at plunge point as a function of free jet length for vertical circular water jets. The data were incorporated into a model to predict air-entrainment rate. McCarthy and Molloy (1972) studied the stability of liquid jets and the influence of nozzle design. In this study, effective jet width $\left(b_{j}\right)$, volumetric airflow rate $\left(Q_{a}\right)$, air-entrainment rate $\left(\mathrm{Q}_{\mathrm{a}} / \mathrm{Q}_{\mathrm{w}}\right)$, and penetration depth $\left(\mathrm{H}_{\mathrm{p}}\right)$ were studied in a plunging jet system using an inclined rectangular nozzles with rounded ends. An empirical correlation for the inclined rectangular nozzles with rounded ends are presented to predict airentrainment rate $\left(\mathrm{Q}_{\mathrm{a}} / \mathrm{Q}_{\mathrm{w}}\right)$ as a function of effective jet expansion ratio $\left(b_{j} / b_{n}\right)$.

\section{Experimental}

Figures 1 and 2 show experimental apparatus and details of the nozzle used, respectively. The experimental apparatus consists of a recirculation pump and a water tank of $1.0 \mathrm{~m}$ long, $1.0 \mathrm{~m}$ deep, and $0.70 \mathrm{~m}$ wide, made of glass. The total water volume in these jet systems, which also includes the volume in circulation pipes, was held constant at $0.500 \mathrm{~m}^{3}$. A water rotameter was used to measure water discharge recirculated by the water pump. An inlet valve was settled to adjust water discharge. The bubbles were collected under a bubble trap. An air rotameter was installed on the bubble trap to measure the values of volumetric airflow rate.

Nozzles were made of copper. The preferred nozzle outlet geometry was a rectangular with rounded ends to prevent energy losses of rectangle corners. This nozzle outlet geometry was produced by contracting circular nozzle outlet. Nozzle contraction ratio $\left(b_{n} / d_{n}\right)$ was selected to be 1.20 . Nozzle length $\left(L_{n}\right)$ used in this study was $50 \mathrm{~mm}$. Cross section of nozzle inlet is circular. Nozzles with inlet diameter $\left(\mathrm{d}_{\mathrm{n}}\right)$ of $4.7 \mathrm{~mm}$ and $7.5 \mathrm{~mm}$ were used in the experiments. The outlet height $\left(a_{n}\right)$ of the nozzles was 3.5 and 5.0 $\mathrm{mm}$ and outlet width $\left(\mathrm{b}_{\mathrm{n}}\right)$ of the nozzles was $5.5 \mathrm{~mm}$ and $9.8 \mathrm{~mm}$. The free jet length $\left(\mathrm{L}_{\mathrm{i}}\right)$ was varied as $150 \mathrm{~mm}$ and $200 \mathrm{~mm}$. The angle between the water jet and the free water surface of the pool was selected as $45^{\circ}$. The maximum bubble penetration depth was determined with a scale attached to the tank wall. Moreover, effective jet width was simply measured with a millimetric scale. 


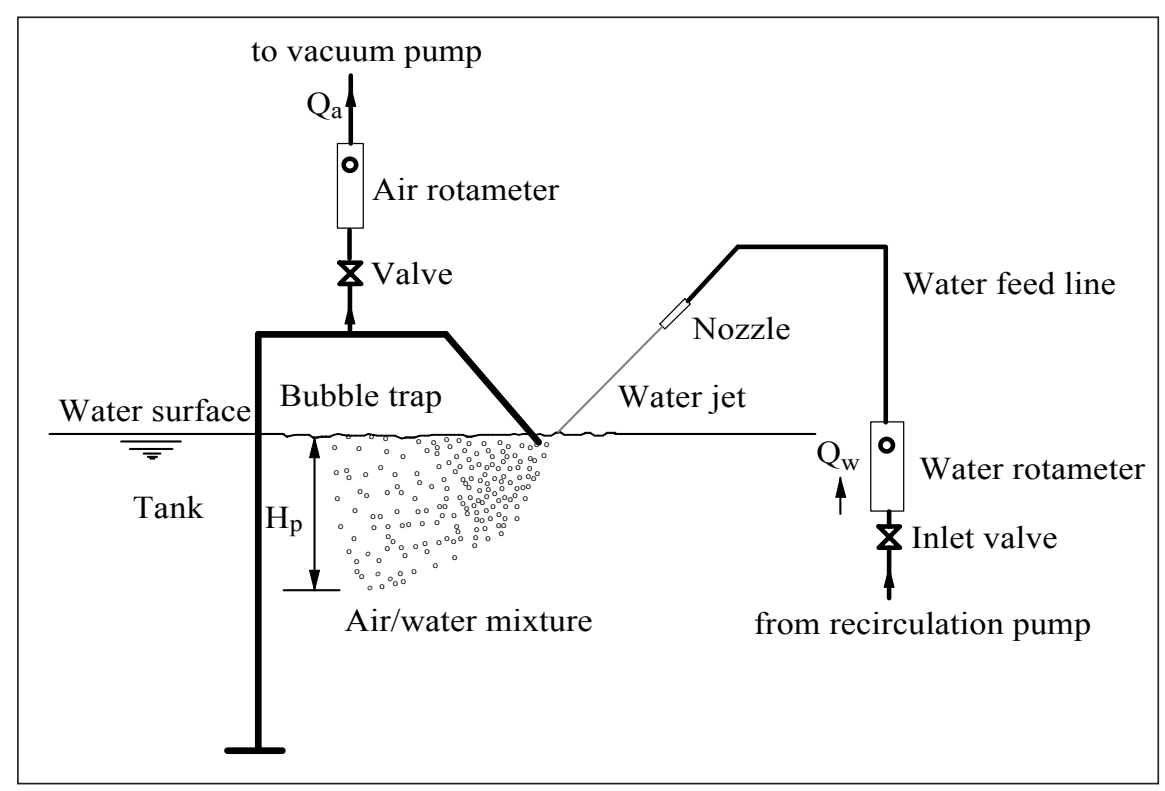

Figure 1

Experimental set-up for the water jet system

Inlet

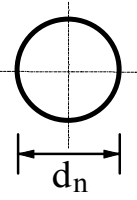

Nozzle

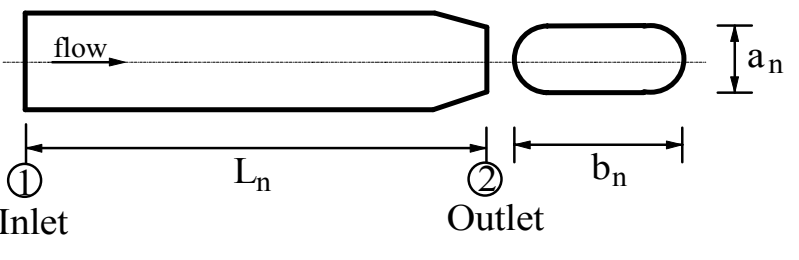

Figure 2

Detail of nozzle design

\section{Results and discussion}

\section{Free jet expansion}

In this study, the effect of nozzle design on the expansion of the water jet at impact point was studied for rectangular nozzles with rounded ends. Figure 3 shows effective jet width $\left(b_{j}\right)$ at plunge point. Effective jet width (b $b_{j}$ was measured between $10 \mathrm{~mm}$ and $50 \mathrm{~mm}$. Figure 4 also shows variation in effective jet expansion ratio $\left(b_{j} / b_{n}\right)$ with jet velocity $\left(\mathrm{V}_{\mathrm{j}}\right)$ for inlet diameter $\left(\mathrm{d}_{\mathrm{n}}\right)$ and jet length $\left(L_{j}\right)$. Effective jet expansion ratio $\left(b_{j} / b_{n}\right)$ increased as $\mathrm{V}_{\mathrm{j}}$ increased. This may be caused by air friction forces and geometry of the nozzle outlet.

\section{Air bubble penetration depth}

Bubble penetration depth $\left(\mathrm{H}_{\mathrm{p}}\right)$ is defined as the vertical distance between the free surface of the tank filled with water to the lower end of submerged two-phase (gas-liquid) region in the water body. Figure 5 shows results of $\mathrm{H}_{\mathrm{p}}$ in which $\mathrm{H}_{\mathrm{p}}$ is plotted vs. $\left(\mathrm{V}_{\mathrm{j}}\right)$. The values of $\mathrm{H}_{\mathrm{p}}$ are constant until the values of $\left(\mathrm{V}_{\mathrm{j}}\right)$ reach $7 \mathrm{~m} / \mathrm{s}$. Moreover, the values of $\mathrm{H}_{\mathrm{p}}$ begin to increase above the value of $7 \mathrm{~m} / \mathrm{s}$ for $\left(\mathrm{V}_{\mathrm{j}}\right)$. The increase in $\mathrm{H}_{\mathrm{p}}$ may be attributed to the increased momentum of the water jet flow.

Figure 6 shows results of $\mathrm{H}_{\mathrm{p}}$ in which $\mathrm{H}_{\mathrm{p}}$ is plotted vs. $\left(b_{j} / b_{n}\right)$. The values of $H_{p}$ are constant until the values of $\left(b_{j} / b_{n}\right)$ reach 3.5. This may be attributed to the increased buoyancy forces of the entrained air bubbles as a result of the increase in the volumetric airflow rate. Jet velocity $\left(\mathrm{V}_{\mathrm{j}}\right)$ to the value of 3.5 for $\left(b_{i} / b_{n}\right)$ was calculated to be higher than $5 \mathrm{~m} / \mathrm{s}$. Moreover, the values of $\mathrm{H}_{\mathrm{p}}$ begin to increase above the value of 3.5 for $\left(b_{i} / b_{n}\right)$. Increases in $\mathrm{H}_{\mathrm{p}}$ may be attributed to the increased momentum of the water jet.

\section{Volumetric airflow rate}

Entrained air by water jets was collected under the "bubble trap" and absorbed by vacuum pump (see Fig. 1). Thus, volumetric airflow rate $\left(\mathrm{Q}_{\mathrm{a}}\right)$ was measured for circular and rectangular nozzles with rounded ends. Figure 7 shows typical effects of $\left(\mathrm{V}_{\mathrm{j}}\right)$, nozzle diameter and nozzle geometry on $\left(\mathrm{Q}_{\mathrm{a}}\right)$. 


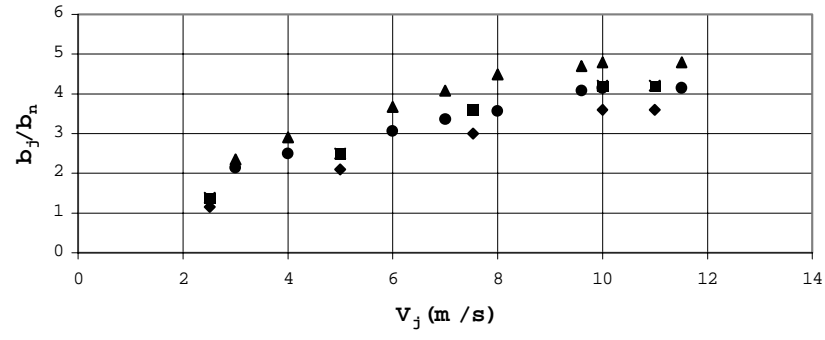

- $\mathrm{d}_{\mathrm{n}}=4.7 \mathrm{~mm}, \mathrm{~L}_{\mathrm{j}}=15 \mathrm{~cm}$

- $\mathrm{d}_{\mathrm{n}}=7.5 \mathrm{~mm}, \mathrm{~L}_{\mathrm{j}}=15 \mathrm{~cm}$

- $\mathrm{d}_{\mathrm{n}}=4.7 \mathrm{~mm}, \mathrm{~L}=20 \mathrm{~cm}$

$\Delta \mathrm{d}_{\mathrm{n}}=7.5 \mathrm{~mm}, \mathrm{~L}_{\mathrm{j}}=20 \mathrm{~cm}$

Figure 4

Influence of jet velocity on jet expansion ratio in rectangular nozzles with rounded ends

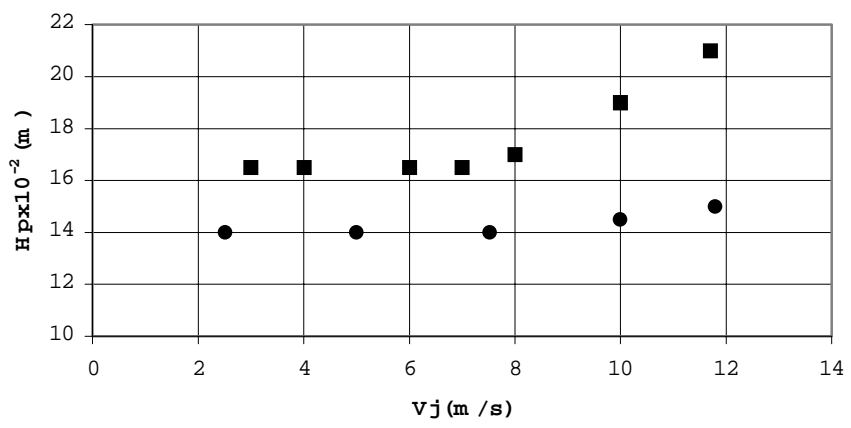

- $\mathrm{d}_{\mathrm{n}}=7.5 \mathrm{~mm}, \mathrm{~L}_{\mathrm{j}}=15 \mathrm{~cm}$

- $d_{n}=4.7 \mathrm{~mm}, L_{j}=15 \mathrm{~cm}$

Figure 5

Effect of jet velocity on bubble penetration depth in rectangular nozzles with rounded ends

The increase in $\mathrm{Q}_{\mathrm{a}}$ with increases in $\mathrm{V}_{\mathrm{j}}$ and nozzle diameter may be attributed to the increased momentum of the jet flow, contacting perimeter between the jet flow and the water surface, roughness of the jet surface, and variation of jet shape depending on nozzle geometry. Rectangular nozzles with rounded ends were observed to have higher volumetric airflow rate than circular nozzle. This is the reason why the rectangular nozzles with rounded ends carries more air due to the expansion of the jet surface depending on jet velocity

\section{Air-entrainment rate}

Air-entrainment rate $\left(\mathrm{Q}_{\mathrm{a}} / \mathrm{Q}_{\mathrm{w}}\right)$ is a measure of aeration performance of the plunging water jets. Figure 8 shows the effect of jet expansion ratio $\left(b_{j} / b_{n}\right)$ on air-entrainment rate $\left(Q_{a} / Q_{w}\right)$. For predicting the airentrainment rate $\left(Q_{a} / Q_{w}\right)$ in rectangular nozzles with rounded ends, an empirical correlation was found depending on effective jet expansion ratio $\left(b_{i} / b_{n}\right)$, as shown in Eq.(2). This experimental correlation is similar to expression given by Henderson et al. (1970) for circular water jets, as shown in Eq.(1).

$$
\mathrm{Q}_{\mathrm{a}} / \mathrm{Q}_{\mathrm{w}}=\left(\mathrm{b}_{\mathrm{j}} / \mathrm{b}_{\mathrm{n}}\right)-1
$$

\section{Conclusions}

Air-entrainment characteristics of rectangular nozzles with rounded ends in plunging water jets were investigated. Based on the

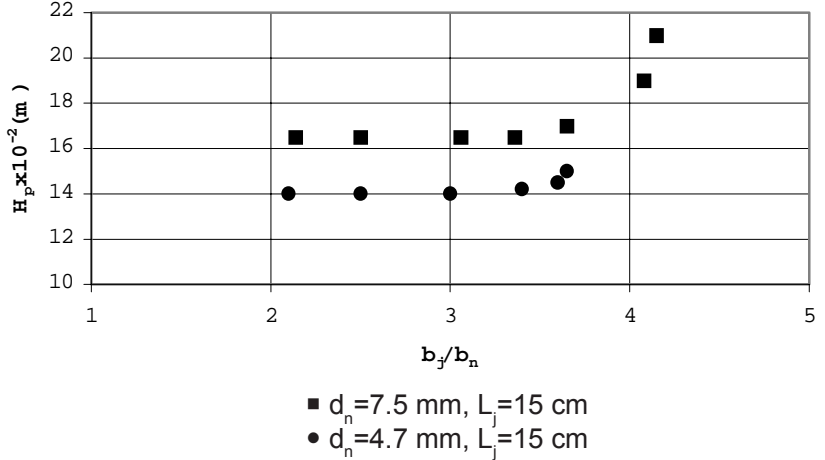

Figure 6

Effect of jet expansion ratio on bubble penetration depth in rectangular nozzles with rounded ends

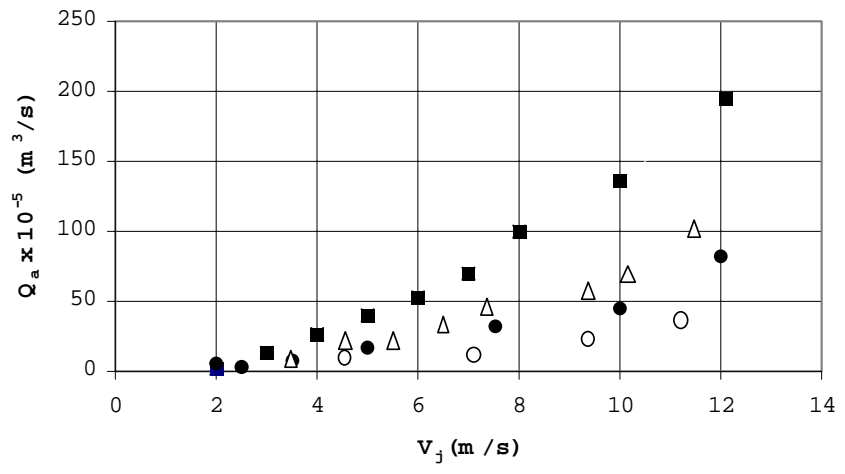

$\circ \mathrm{d}_{\mathrm{n}}=4.7 \mathrm{~mm}, \mathrm{~L}_{\mathrm{j}}=15 \mathrm{~cm}$ (circular nozzle)

$\triangle d_{n}=7.5 \mathrm{~mm}, L_{j}=15 \mathrm{~cm}$ (circular nozzle)

- $\mathrm{d}_{\mathrm{n}}=4.7 \mathrm{~mm}, \mathrm{~L}=15 \mathrm{~cm}$ (rectangular nozzle with rounded ends)

- $d_{n}=7.5 \mathrm{~mm}, L_{j}=15 \mathrm{~cm}$ (rectangular nozzle with rounded ends)

\section{Figure 7}

Variation of volumetric airflow rate with water velocity in circular and rectangular nozzles with rounded ends

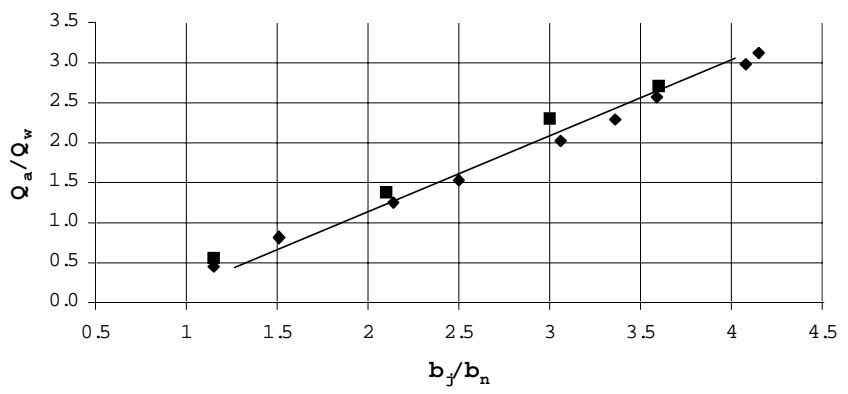

- $\mathrm{d}_{\mathrm{n}}=4.7 \mathrm{~mm}, \mathrm{~b}_{\mathrm{n}}=5.5 \mathrm{~mm}$

- $d_{n}=7.5 \mathrm{~mm}, b_{n}=9.8 \mathrm{~mm}$

Figure 8

Relationship between air-entrainment rate and jet expansion ratio in rectangular nozzles with rounded ends

findings of this study, the following conclusions can be drawn:

- Free jet expansion rectangular nozzles with rounded ends significantly increased as water jet velocity increased. Jet expansion in rectangular nozzles with rounded ends reached approximately five times nozzle outlet width. Increasing free jet expansion led to higher volumetric airflow rate. 
- Air bubble penetration depth in rectangular nozzles with rounded ends was constant with jet expansion ratio up to a certain point and then increased with a further increase of jet expansion ratio.

- Volumetric airflow rate for rectangular nozzles with rounded ends was observed higher than for circular nozzles, because a circular nozzle does not have to expand as much as the rectangular nozzle with rounded ends. Rectangular nozzles with rounded ends carry more air due to the expansion of the jet surface depending on jet velocity. Therefore, using simple rectangular nozzles with rounded ends instead of circular nozzles could significantly increase volumetric airflow rate. Moreover, Bagatur et al. (2002) showed that it is appropriate to use rectangular nozzles with rounded ends in the applications where high air bubble concentration is desirable.

- For rectangular nozzles with rounded ends, the relationship between air-entrainment rate and jet expansion ratio was observed as linear. An empirical correlation for predicting airentrainment rate in rectangular nozzles with rounded ends was found depending on effective jet expansion ratio.

\section{References}

BAGATUR T, BAYLAR A and SEKERDAG N (2002) The effect of nozzle type on air-entrainment by plunging water jets. Water Qual. Res. Can. 37 (3) 599-612.

BIN AK (1993) Gas entrainment by plunging liquid jets. Chem. Eng. Sci. 48 3585-3630.

EVANS GM, JAMESON GJ and RIELLY CD (1996) Free jet expansion and gas entrainment characteristics of a plunging liquid jet. Exper. Therm. Fluid Sci. 12 142-149.

HENDERSON JB, McCARTHY MJ and MOLLOY NA (1970)Entrainment by plunging Jets. Proc. Chemeca'70, Australia, Sec. 2, 86-100.

McCARTHY MJ and MOLLOY NA (1972) Review of stability of liquid jets and the Influence of nozzle design. Chem. Eng. J. 7 1-20. 